\title{
Sensitive Electrochemical Detection of Glucose at Glucose Oxidase-Cobalt Phthalocyanine-Modified Boron-Doped Diamond Electrode
}

\author{
Takeshi Kondo, ${ }^{1,2}$ Masaru Horitani, ${ }^{1}$ and Makoto Yuasa ${ }^{1,2}$ \\ ${ }^{1}$ Department of Pure and Applied Chemistry, Faculty of Science and Technology, Tokyo University of Science, 2641 Yamazaki, \\ Noda 278-8510, Japan \\ ${ }^{2}$ Reaserach Institute for Science and Technology, Tokyo University of Science, 2641 Yamazaki, Noda 278-8510, Japan
}

Correspondence should be addressed to Takeshi Kondo, t-kondo@rs.noda.tus.ac.jp

Received 7 May 2011; Revised 28 July 2011; Accepted 1 August 2011

Academic Editor: Giancarlo R. Salazar-Banda

Copyright (c) 2012 Takeshi Kondo et al. This is an open access article distributed under the Creative Commons Attribution License, which permits unrestricted use, distribution, and reproduction in any medium, provided the original work is properly cited.

\begin{abstract}
Electrochemical detection of glucose was achieved at a glucose oxidase (GOx)-cobalt phthalocyanine (CoPc)-modified borondoped diamond (BDD) electrode without any additional electron mediator in the electrolyte solution. The surface of the hydrogen-terminated BDD thin film prepared by microwave plasma-assisted CVD was modified with 4-vinylpyridine (4VP) via photochemical modification. The $4 \mathrm{VP}-\mathrm{BDD}$ was then immersed in a CoPc solution to obtain $\mathrm{CoPc}-\mathrm{BDD}$. A poly $(p-$ phenylenediamine) (PPD) thin film containing GOx was coated on the CoPc-BDD electrode surface via electropolymerization. At the GOx/PPD-CoPc-BDD electrode, anodic current for glucose oxidation was observed with a sigmoidal voltammetric curve, indicating successful electron mediation of $\mathrm{H}_{2} \mathrm{O}_{2}$ generated as the result of glucose oxidation at GOx. The signal-to-background ratio for voltammetric current of glucose detection was larger at the GOx/PPD-CoPc-BDD electrode than at the GOx/PPDmodified platinum electrode due to the smaller background current of the modified BDD electrode.
\end{abstract}

\section{Introduction}

Highly boron-doped diamond (BDD) electrodes have been known to be a promising electrode material for sensitive electroanalysis based on the wide potential window and low background current as well as physical and chemical stability and biocompatibility [1]. Glucose is a compound, whose concentration is one of the most desired to be determined via electrochemical methods in relation to increasing demands for diabetes care [2]. In order to use BDD electrode for glucose detection, one should modify the surface with catalysts or enzymes due to the large overpotential for direct glucose oxidation at unmodified BDD electrodes. For glucose detection at BDD electrodes using electrocatalysts, $\mathrm{Cu}$ [3-5] and $\mathrm{Ni}[6-9]$ have been used for modification of the surfaces. Immobilization of particles or line patterns of these metals with micrometer or nanometer scale onto BDD surface enables sensitive glucose detection with low background current. On the other hand, BDD electrodes modified with glucose oxidase (GOx) [10-13] are advantageous because of their selectivity and sensitivity of the glucose molecule. In some cases, additional mediators, such as ferrocene carboxylic acid [11], were employed for glucose detection at GOx-modified BDD electrodes. Glucose detection without any additional reagents to samples is possible for simple analysis systems, and especially for monitoring concentration. Hydrogen peroxide is a product of glucose oxidation at GOx and thus can act as an electroactive mediator for electrochemical detection of glucose. We have reported that sensitive electrochemical detection of hydrogen peroxide can be achieved at BDD electrodes modified with cobalt(II) phthalocyanine $(\mathrm{CoPc})$ [14]. The limit of detection of hydrogen peroxide at CoPc-BDD electrode using a flowinjection system was found to be in the range of $1-10 \mathrm{nM}$ and that was rather low comparing to Pt-modified BDD electrodes $(30 \mathrm{nM})$ [15]. Thus the use of CoPc-BDD should be effective for fabrication of a GOx-modified BDD electrodes for sensitive glucose detection. In the present study, we prepared a GOx containing poly( $p$-phenylenediamine) (PPD) film on a CoPc-BDD electrode surface to fabricate an 

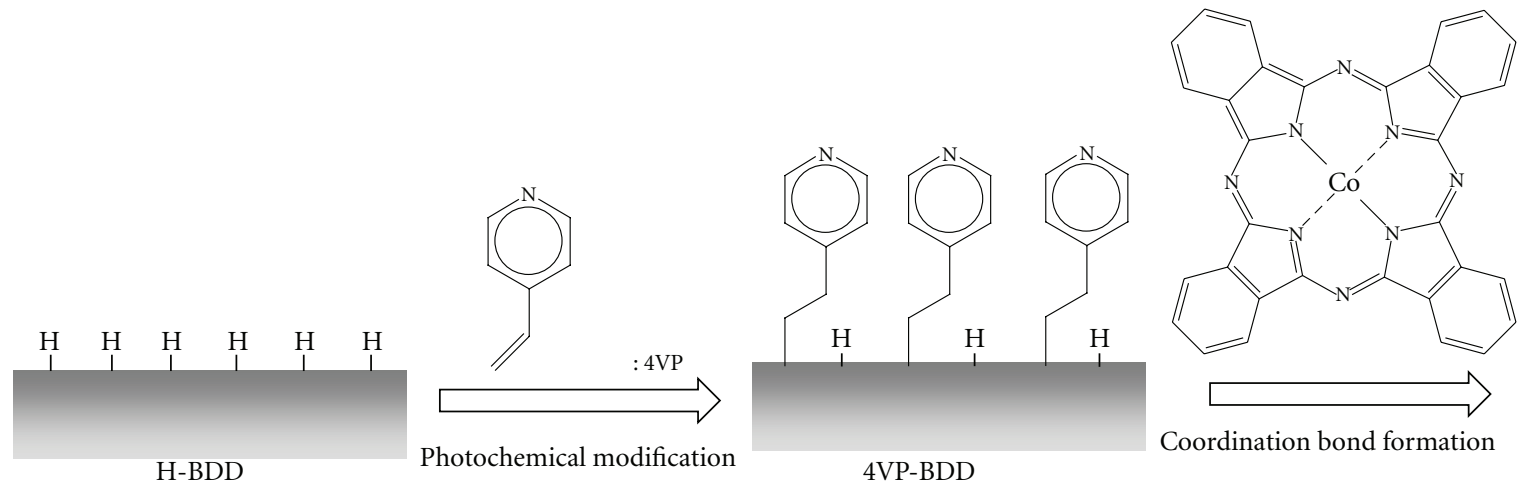

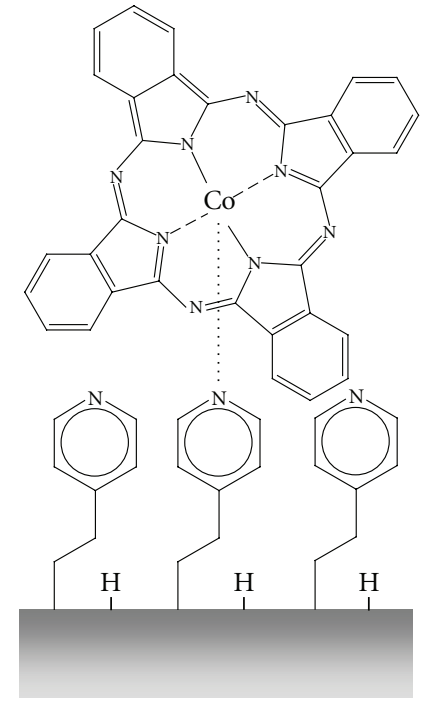

CoPc-BDD

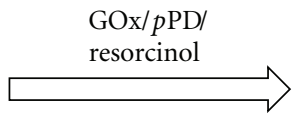

Electropolymerization

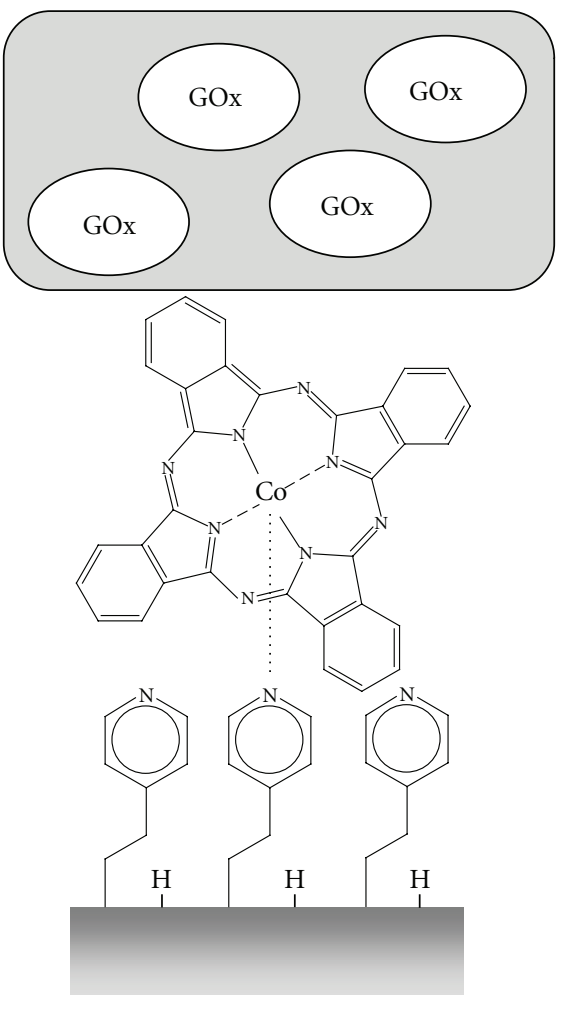

GOx/PPD-CoPc-BDD

Scheme 1: Fabrication of GOx/PPD-CoPc-BDD electrode.

electrode material for reagentless sensitive glucose detection (Scheme 1). The signal-to-background ratio of glucose was found to be larger at GOx/PPD-CoPc-BDD electrode than at GOx/PPD-Pt electrode.

\section{Experimental}

BDD electrodes were prepared by microwave plasma-assisted chemical vapor deposition (MPCVD). The deposition condition was identical to what can be found in our previous report [16]. A conductive polycrystalline BDD thin film with a grain size of $1-5 \mu \mathrm{m}$ was first grown on a conductive silicon wafer substrate. Surface modification of BDD with $\mathrm{CoPc}$ was carried out with a procedure described in the previous report [14]. A hydrogen-terminated BDD (H-BDD) sample was immersed in a $100 \mathrm{mM}$ 4-vinylpyridine (4VP)/acetonitrile solution. The sample surface was then irradiated with UV light $(254 \mathrm{~nm})$ from a low pressure mercury lamp (SUV-40, Sen Lights Corp.) in Ar atmosphere through a quartz window for $3 \mathrm{~h}$. The $4 \mathrm{VP}$-modified $\mathrm{BDD}$ sample was then immersed in a $0.1 \mathrm{mM} \mathrm{CoPc/chloroform} \mathrm{solution} \mathrm{for}$ one day to obtain CoPc-BDD. Surface modification with $4 \mathrm{VP}$ and $\mathrm{CoPc}$ was confirmed with $\mathrm{X}$-ray photoelectron spectroscopy (XPS) with a XP spectrometer (AXIS-NOVA, Kratos). GOx/PPD film was prepared using an electropolymerization method. Potential cycling, repeated 10 times, between 0 to $+0.6 \mathrm{~V}$ versus $\mathrm{Ag} / \mathrm{AgCl}$ was performed in $0.1 \mathrm{M}$ phosphate buffer solution (PBS, $\mathrm{pH} 7$ ) containing $0.15 \mathrm{mM}$ $p$-phenylenediamine, $0.15 \mathrm{mM}$ resorcinol, and $500 \mathrm{U} / \mathrm{mL}$ glucose oxidase (Type VII, from aspergillus niger, SigmaAldrich) at a CoPc-BDD electrode at a potential sweep rate of $20 \mathrm{mVs}^{-1}$. For all electrochemical experiments, an 


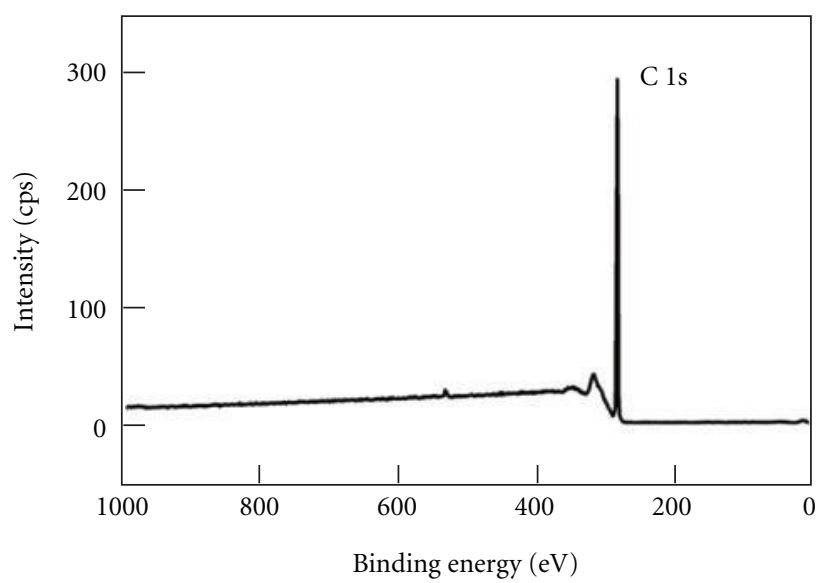

(a) H-BDD

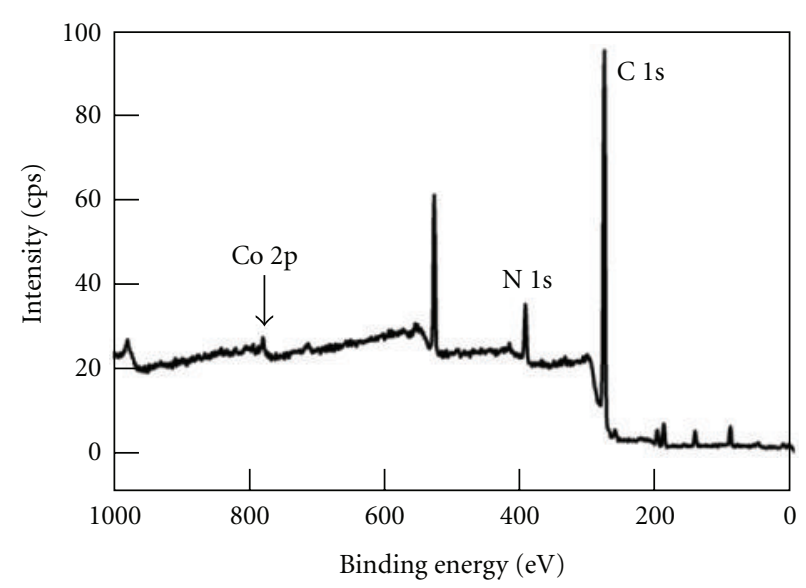

(c) $\mathrm{CoPc}-\mathrm{BDD}$

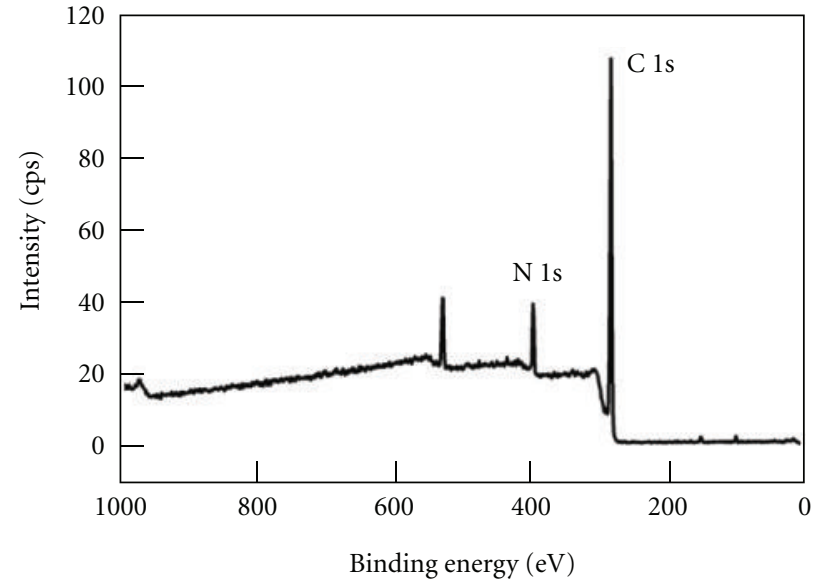

(b) 4VP-BDD

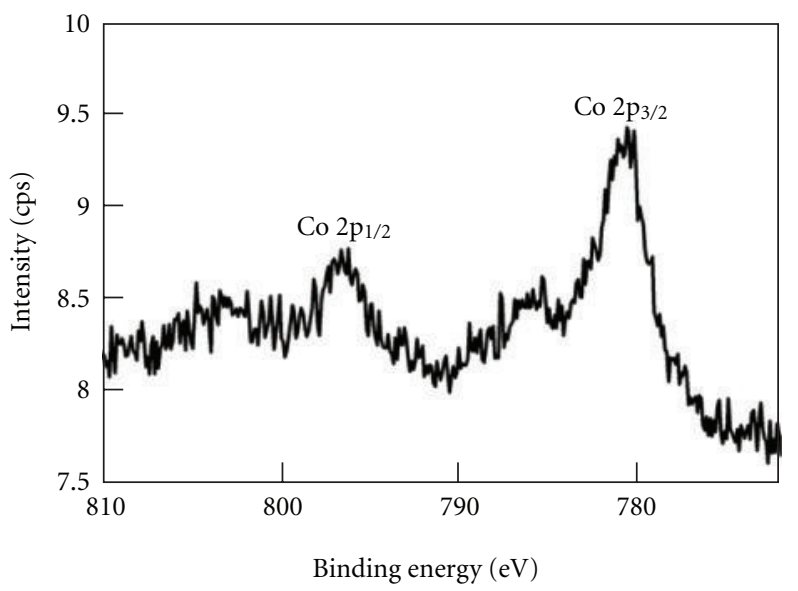

(d) CoPc-BDD (Co 2p)

Figure 1: XPS of (a) H-, (b) 4VP-, and (c) CoPc-BDD surfaces. (d) Co 2p spectrum of CoPc-BDD surface.

$\mathrm{Ag} / \mathrm{AgCl}$ electrode with saturated $\mathrm{KCl}$ and a platinum spiral wire were used for a reference and a counter electrode, respectively, connecting to a digital potentiostat (HZ-5000, Hokuto Denko).

\section{Results and Discussion}

3.1. Preparation of $C o P c-B D D$ Electrode. Surface modification of BDD with $4 \mathrm{VP}$ was confirmed with XPS. After surface modification with $4 \mathrm{VP}$, an $\mathrm{N}$ 1s peak was shown in the XP spectra at $397 \mathrm{eV}$ (Figure 1(b)), which was absent in the spectrum of H-BDD (Figure 1(a)). This should be based on the pyridine moiety on the $4 \mathrm{VP}-\mathrm{BDD}$ surface. The N/C atomic concentration ratio determined from XPS quantitative analysis was found to saturate with between 2 and $3 \mathrm{~h}$ UV irradiation. Thus, we decided the UV irradiation time for the 4VP modification to be $3 \mathrm{~h}$. Immobilization of CoPc on 4VP-BDD surface was also confirmed with Co $2 \mathrm{p}_{3 / 2}$ and $(781 \mathrm{eV})$ Co $2 \mathrm{p}_{1 / 2}(797 \mathrm{eV})$ peaks (Figure $1(\mathrm{c})$ ). The Co/C atomic concentration ratio saturated within $24 \mathrm{~h}$ of immersion of a $4 \mathrm{VP}-\mathrm{BDD}$ in a CoPc solution. Figure 2 shows cyclic voltammograms (CVs) in $0.1 \mathrm{M}$ phosphate

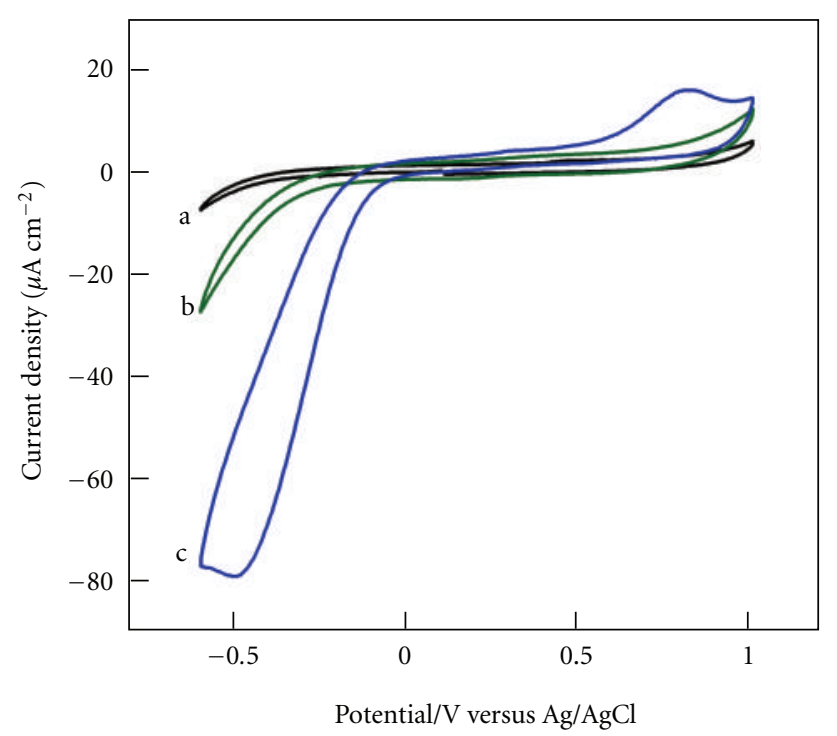

Figure 2: CVs in 0.1 M PBS at (a) H-, (b) 4VP-, and (c) CoPc-BDD electrodes. Potential sweep rate was $100 \mathrm{mVs}^{-1}$. 


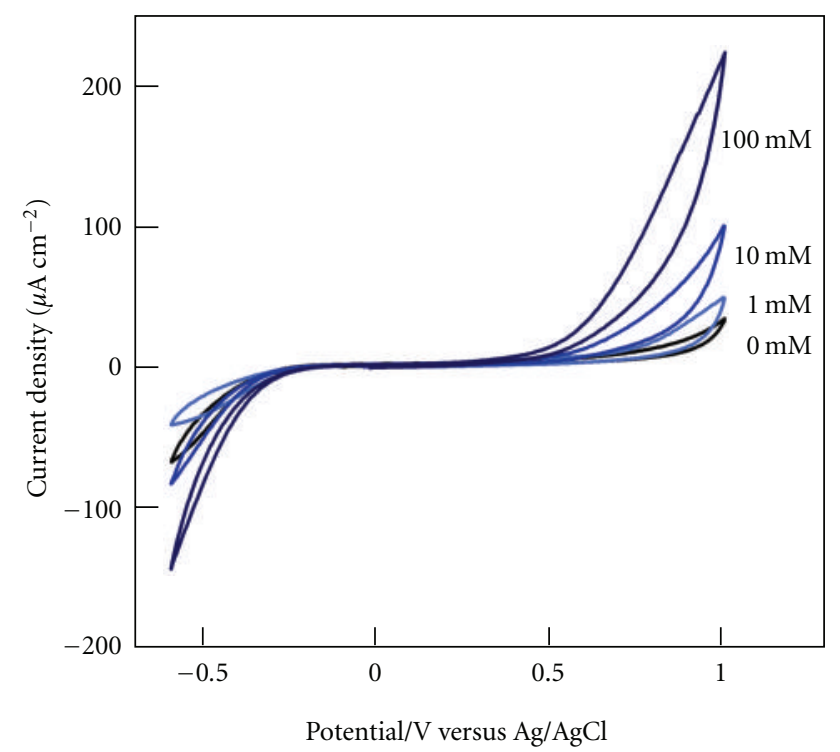

Figure 3: CVs in $0.1 \mathrm{M}$ PBS containing $0,1,10$, and $100 \mathrm{mM} \mathrm{H}_{2} \mathrm{O}_{2}$ at CoPc-BDD electrode. Potential sweep rate was $100 \mathrm{mVs}^{-1}$.

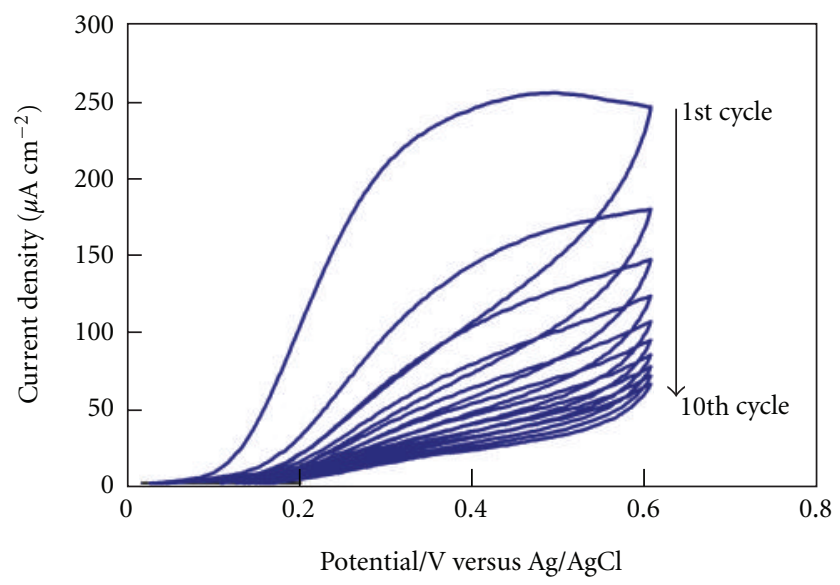

Figure 4: CVs in $0.1 \mathrm{M}$ PBS containing $0.15 \mathrm{mM}$ p-phenylenediamine, $0.15 \mathrm{mM}$ resorcinol and $500 \mathrm{U} / \mathrm{mL}$ GOx at CoPcBDD electrode for electropolymerization of a GOx/PPD film. Ten successive cycles are indicated. Potential sweep rate was $20 \mathrm{mVs}^{-1}$.

buffer solution (PBS, pH 7) at modified BDD electrodes. Although no redox peak was found in the CVs at $\mathrm{H}$ - and 4VP-BDD electrode, an anodic and a cathodic peak was found at the CoPc-BDD electrode. This result indicates that the immobilized CoPc was redox-active on the modified electrode [14]. Figure 3 shows CVs at CoPc-BDD electrode in $0.1 \mathrm{M}$ PBS containing various concentrations of $\mathrm{H}_{2} \mathrm{O}_{2}$. At unmodified (H-terminated) BDD surface, no increase of the faradaic current for $\mathrm{H}_{2} \mathrm{O}_{2}$ was found. This is due to a large overpotential of the electrode reaction of $\mathrm{H}_{2} \mathrm{O}_{2}$ at the unmodified BDD electrode. On the other hand, the $\mathrm{CV}$ at CoPc-BDD showed an anodic and cathodic faradaic current depending on $\mathrm{H}_{2} \mathrm{O}_{2}$ concentration, based on the electrocatalytic activity of CoPc to the electrode reaction of $\mathrm{H}_{2} \mathrm{O}_{2}$ [17].

3.2. Preparation of $G O x / P P D-C o P c-B D D$ Electrode. In order to immobilize GOx onto the electrode surface, GOx/PPD film was formed via electropolymerization method. Figure 4 shows ten successive CVs for the electropolymerization in $0.1 \mathrm{MPBS}$ containing $0.15 \mathrm{mM}$-phenylenediamine, $0.15 \mathrm{mM}$ resorcinol and $500 \mathrm{U} / \mathrm{mL}$ GOx at CoPc-BDD electrode. The decrease in the anodic current is typical of electropolymerization of similar polymer films and is based on the insulating properties of the film formed at the interface [18]. Figure 5 shows scanning electron microscopy (SEM) images of a BDD and a GOx/PPD-CoPc-BDD electrode surfaces. PPD is known to be a stiff polymer with a ladderlike network structure [19], and it should be responsible for the linear texture of the film observed with SEM. In addition, the PPD film formed with electropolymerization method is known to be a permselective membrane for $\mathrm{H}_{2} \mathrm{O}_{2}$ [19] and can suppress electrode reaction of electroactive interferences such as ascorbic acid and dopamine [14]. Thus, the use of PPD matrices should be advantageous for selective detection of glucose.

3.3. Glucose Detection. Figure 6(a) shows a CV in $0.1 \mathrm{M}$ PBS containing $5 \mathrm{mM}$ glucose at a GOx/PPD-CoPc-BDD electrode. In the absence of glucose, almost no current was observed. However, in the presence of glucose, anodic current began to flow at $+0.15 \mathrm{~V}$ versus $\mathrm{Ag} / \mathrm{AgCl}$ and was almost constant at $+0.3 \mathrm{~V}$ versus $\mathrm{Ag} / \mathrm{AgCl}$ or more positive potentials. This sigmoidal curve is typical of enzyme electrode reactions [11], indicating successful electron transfer from glucose to the BDD electrode. In the case of an electrode with a GOx/PPD film formed on the H-BDD surface (GOx/PPD$\mathrm{H}-\mathrm{BDD}$ ), no current response was observed in the presence of glucose in the electrolyte solution (Figure 6(b)). These results indicate that the current response observed for GOx/PPD-CoPc-BDD was not with direct electron transfer from glucose or GOx and should be based on the mediation of $\mathrm{H}_{2} \mathrm{O}_{2}$ electrooxidation catalyzed by the $\mathrm{CoPc}$ on the BDD surface. Thus, it was shown that electrocatalysts, such as $\mathrm{CoPc}$, are essential for the current response of $\mathrm{BDD}$ based enzyme electrodes using oxidases that can generate $\mathrm{H}_{2} \mathrm{O}_{2}$. Similar to the case of GOx/PPD-CoPc-BDD electrode, a sigmoid-shaped voltammetric curve was shown at a $\mathrm{Pt}$ electrode covered with a GOx/PPD film via electropolymerization (GOx/PPD-Pt, Figure 6(c)). This result was not surprising because $\mathrm{H}_{2} \mathrm{O}_{2}$ can be oxidized on a Pt electrode at low potentials without the use of any additional catalyst. The signal current at $+0.5 \mathrm{~V}$ versus $\mathrm{Ag} / \mathrm{AgCl}$ was larger at $\mathrm{GOx} / \mathrm{PPD}$ Pt electrode $\left(54 \mu \mathrm{A} \mathrm{cm}^{-2}\right)$ than at GOx/PPD-CoPc-BDD electrode $\left(25 \mu \mathrm{A} \mathrm{cm}^{-2}\right)$. On the other hand, however, the background current was much lower at GOx/PPD-CoPcBDD electrode $\left(1.8 \mu \mathrm{A} \mathrm{cm}^{-2}\right)$ than at GOx/PPD-Pt electrode $\left(14 \mu \mathrm{A} \mathrm{cm}^{-2}\right)$. As a result, the signal-to-background (S/B) ratio at this potential was found to be 12.5 at the GOx/PPDCoPc-BDD electrode while that was 3.8 at the GOx/PPDPt electrode. As seen in previous reports, low background 


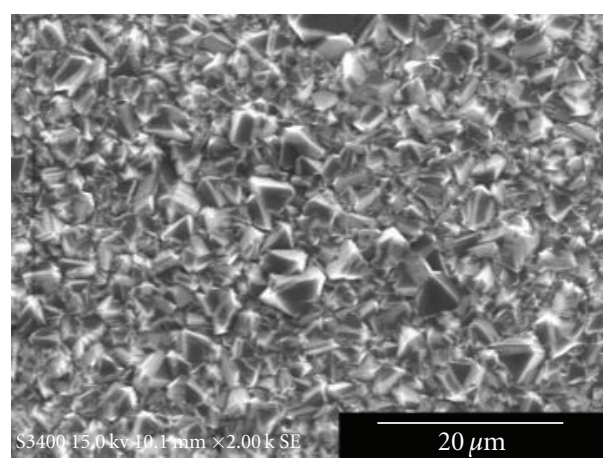

(a)

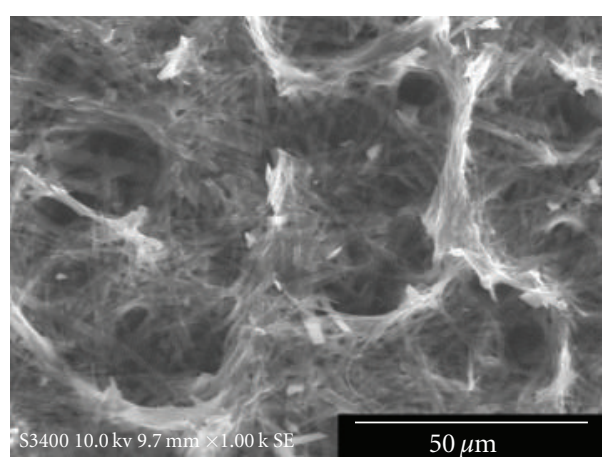

(b)

FIgure 5: SEM image of (a) unmodified BDD and (b) GOx/PPD-CoPc-BDD surface.

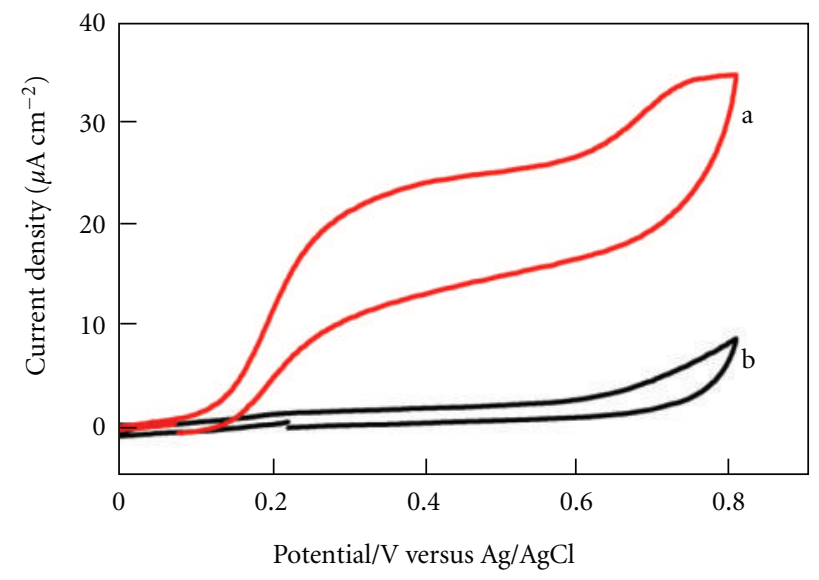

(A) GOx/PPD-CoPc-BDD

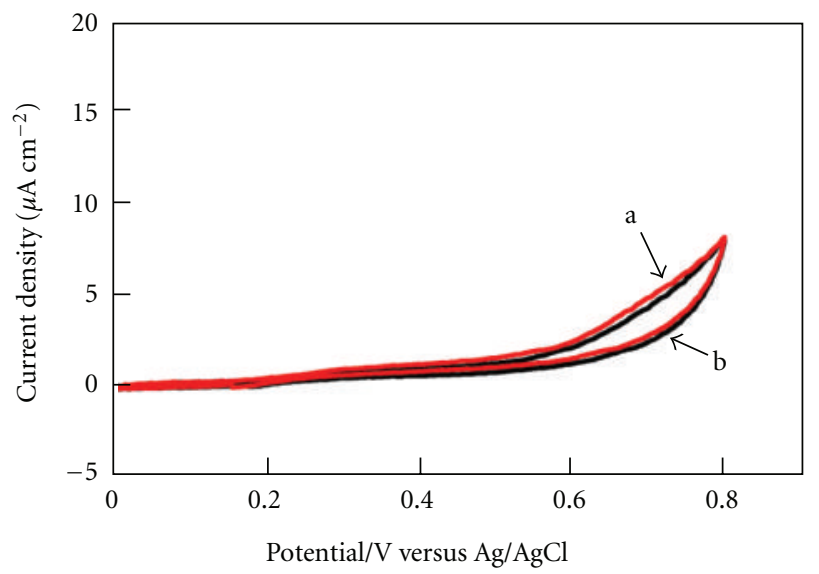

(B) GOx/PPD-H-BDD

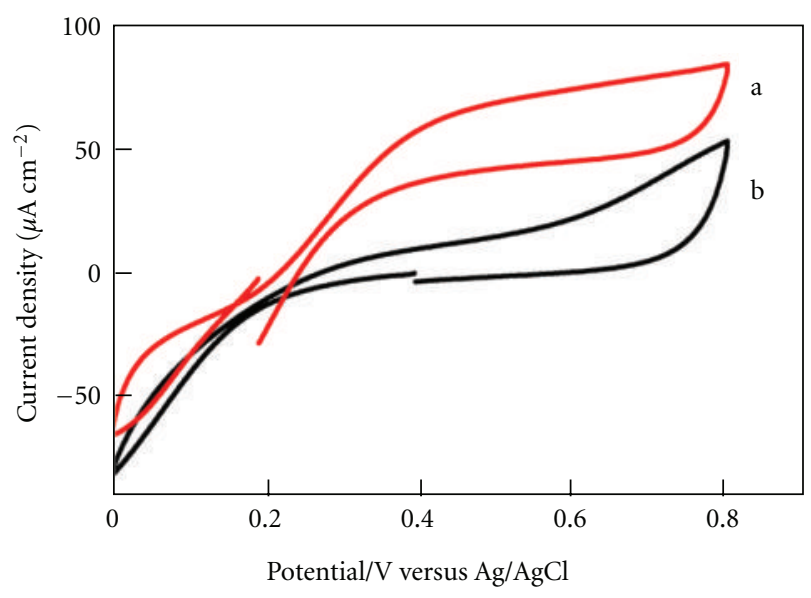

(C) GOx/PPD-Pt

Figure 6: CVs for 5 mM glucose in 0.1 M PBS at (A) GOx/PPD-CoPc-BDD, (B) GOx/PPD-H-BDD, and (C) GOx/PPD-Pt electrodes. Curves (a) and (b) indicate CVs for $5 \mathrm{mM}$ glucose and background, respectively. Potential sweep rate was $5 \mathrm{mVs}^{-1}$.

current at modified BDD electrodes enabled sensitive electrochemical detection of oxalic acid [20] and $\mathrm{H}_{2} \mathrm{O}_{2}$ [14]. Also in this study, the low background current feature of $\mathrm{BDD}$ was maintained even after surface modification with $4 \mathrm{VP}$, CoPc and GOx/PPD film. Therefore, immobilization of enzymes on CoPc-BDD should be a useful method for fabrication of sensitive enzyme electrodes using other types of oxidase which can generate $\mathrm{H}_{2} \mathrm{O}_{2}$ (e.g., uricase, cholesterol oxidase, lactate oxidase, alcohol oxidase, bilirubin oxidase, or choline oxidase) based on the low background current. 


\section{Conclusion}

GOx-immobilized PPD polymer film was formed on a CoPc$\mathrm{BDD}$ electrode via electropolymerization. At the GOx/PPDCoPc-BDD electrode, CV for glucose showed a sigmoidal curve without any additional electron mediator in the electrolyte solution, indicating that the glucose oxidation at the $\mathrm{GOx}$ and the electrocatalytic oxidation of $\mathrm{H}_{2} \mathrm{O}_{2}$, which is a product of glucose oxidation, at the $\mathrm{CoPc}$ were successful at the electrolyte/electrode interface. Since the GOx/PPD-CoPc-BDD electrode exhibited significantly small background current, the $\mathrm{S} / \mathrm{B}$ ratio was found to be larger at the GOx/PPD-CoPc-BDD electrode than at the GOx/PPD-Pt electrode. This result is consistent with our previous result that $\mathrm{H}_{2} \mathrm{O}_{2}$ can be detected electrochemically on the CoPcBDD electrode with the lowest limit of detection level based on the small background current [14]. This study showed that this feature of the CoPc-BDD electrode can be maintained even after further modification with GOx. Therefore, sensitive enzyme electrodes, involved with $\mathrm{H}_{2} \mathrm{O}_{2} / \mathrm{O}_{2}$ redox mediation, having low limit of detection should be able to be fabricated with a similar method using a CoPc-BDD electrode. For application of this electrode to a glucose sensor, amperometric studies using a solution containing glucose and other possible interferents which exist in human blood should be investigated in the future study.

\section{Acknowledgments}

This work was supported by Program for Fostering Regional Innovation in Nagano, granted by MEXT, Japan, KAKENHI (21750209), and Iketani Science and Technology Foundation.

\section{References}

[1] Diamond Electrochemistry, Elsevier, Tokyo, Japan, 2005.

[2] K. E. Toghill and R. G. Compton, "Electrochemical nonenzymatic glucose sensors: a perspective and an evaluation," International Journal of Electrochemical Science, vol. 5, no. 9, pp. 1246-1301, 2010.

[3] T. Watanabe, T. A. Ivandini, Y. Makide, A. Fujishima, and Y. Einaga, "Selective detection method derived from a controlled diffusion process at metal-modified diamond electrodes," Analytical Chemistry, vol. 78, no. 22, pp. 7857-7860, 2006.

[4] J. Zhao, R. Tian, and J. Zhi, "Electroless deposition of copper and fabrication of copper micropatterns on CVD diamond film surfaces," Applied Surface Science, vol. 254, no. 11, pp. 3282-3287, 2008.

[5] M. Chiku, T. Watanabe, and Y. Einaga, "Fabrication of $\mathrm{Cu}-$ modified boron-doped diamond microband electrodes and their application for selective detection of glucose," Diamond and Related Materials, vol. 19, no. 7-9, pp. 673-679, 2010.

[6] R. Uchikado, T. N. Rao, D. A. Tryk, and A. Fujishima, "Metalmodified diamond electrode as an electrochemical detector for glucose," Chemistry Letters, vol. 30, no. 2, pp. 144-145, 2001.

[7] K. Ohnishi, Y. Einaga, H. Notsu et al., "Electrochemical glucose detection using nickel-implanted boron-doped diamond electrodes," Electrochemical and Solid-State Letters, vol. 5, no. 3, pp. D1-D3, 2002.
[8] T. Watanabe and Y. Einaga, "Design and fabrication of nickel microdisk-arrayed diamond electrodes for a non-enzymatic glucose sensor based on control of diffusion profiles," Biosensors and Bioelectronics, vol. 24, no. 8, pp. 2684-2689, 2009.

[9] K. E. Toghill, L. Xiao, M. A. Phillips, and R. G. Compton, "The non-enzymatic determination of glucose using an electrolytically fabricated nickel microparticle modified borondoped diamond electrode or nickel foil electrode," Sensors and Actuators, B, vol. 147, no. 2, pp. 642-652, 2010.

[10] C. E. Troupe, I. C. Drummond, C. Graham et al., "Diamondbased glucose sensors," Diamond and Related Materials, vol. 7, no. 2-5, pp. 575-580, 1998.

[11] L. Su, X. Qiu, L. Guo, F. Zhang, and C. Tung, "Amperometric glucose sensor based on enzyme-modified borondoped diamond electrode by cross-linking method," Sensors and Actuators, B, vol. 99, no. 2-3, pp. 499-504, 2004.

[12] K. B. Male, S. Hrapovic, and J. H. T. Luong, "Electrochemically-assisted deposition of oxidases on platinum nanoparticle/multi-walled carbon nanotube-modified electrodes," Analyst, vol. 132, no. 12, pp. 1254-1261, 2007.

[13] M. J. Song, J. H. Kim, S. K. Lee et al., "Pt-polyaniline nanocomposite on boron-doped diamond electrode for amperometic biosensor with low detection limit," Microchimica Acta, vol. 171, no. 3-4, pp. 249-255, 2010.

[14] T. Kondo, A. Tamura, and T. Kawai, "Cobalt phthalocyaninemodified boron-doped diamond electrode for highly sensitive detection of hydrogen peroxide," Journal of the Electrochemical Society, vol. 156, no. 11, pp. F145-F150, 2009.

[15] T. A. Ivandini, R. Sato, Y. Makide, A. Fujishima, and Y. Einaga, "Pt-implanted boron-doped diamond electrodes and the application for electrochemical detection of hydrogen peroxide," Diamond and Related Materials, vol. 14, no. 11-12, pp. 2133-2138, 2005.

[16] T. Kondo, S. Aoshima, K. Honda, Y. Einaga, A. Fujishima, and T. Kawai, "Fabrication of covalent SAM/Au nanoparticle/boron-doped diamond configurations with a sequential self-assembly method," Journal of Physical Chemistry C, vol. 111, no. 34, pp. 12650-12657, 2007.

[17] P. N. Mashazi, K. I. Ozoemena, and T. Nyokong, "Tetracarboxylic acid cobalt phthalocyanine SAM on gold: potential applications as amperometric sensor for $\mathrm{H}_{2} \mathrm{O}_{2}$ and fabrication of glucose biosensor," Electrochimica Acta, vol. 52, no. 1, pp. 177-186, 2006.

[18] H. H. Weetall, D. W. Hatchett, and K. R. Rogers, "Electrochemically deposited polymer-coated gold electrodes selective for 2,4-dichlorophenoxyacetic acid," Electroanalysis, vol. 17, no. 19, pp. 1789-1794, 2005.

[19] S. J. Killoran and R. D. O'Neill, “Characterization of permselective coatings electrosynthesized on Pt-Ir from the three phenylenediamine isomers for biosensor applications," Electrochimica Acta, vol. 53, no. 24, pp. 7303-7312, 2008.

[20] T. Kondo, Y. Niwano, A. Tamura et al., "Sensitive electrochemical detection of oxalate at a positively charged boron-doped diamond surface," Electroanalysis, vol. 20, no. 14, pp. 15561564, 2008. 


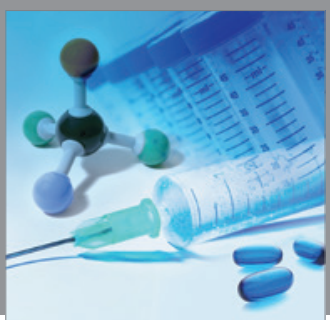

International Journal of

Medicinal Chemistry

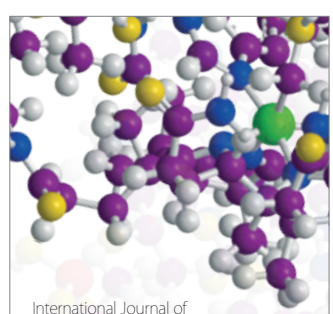

Carbohydrate Chemistry

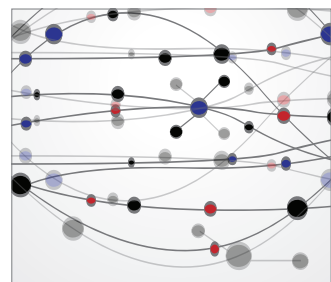

The Scientific World Journal
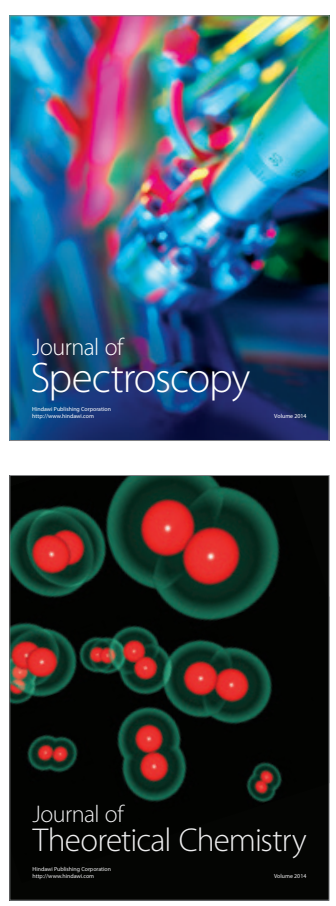
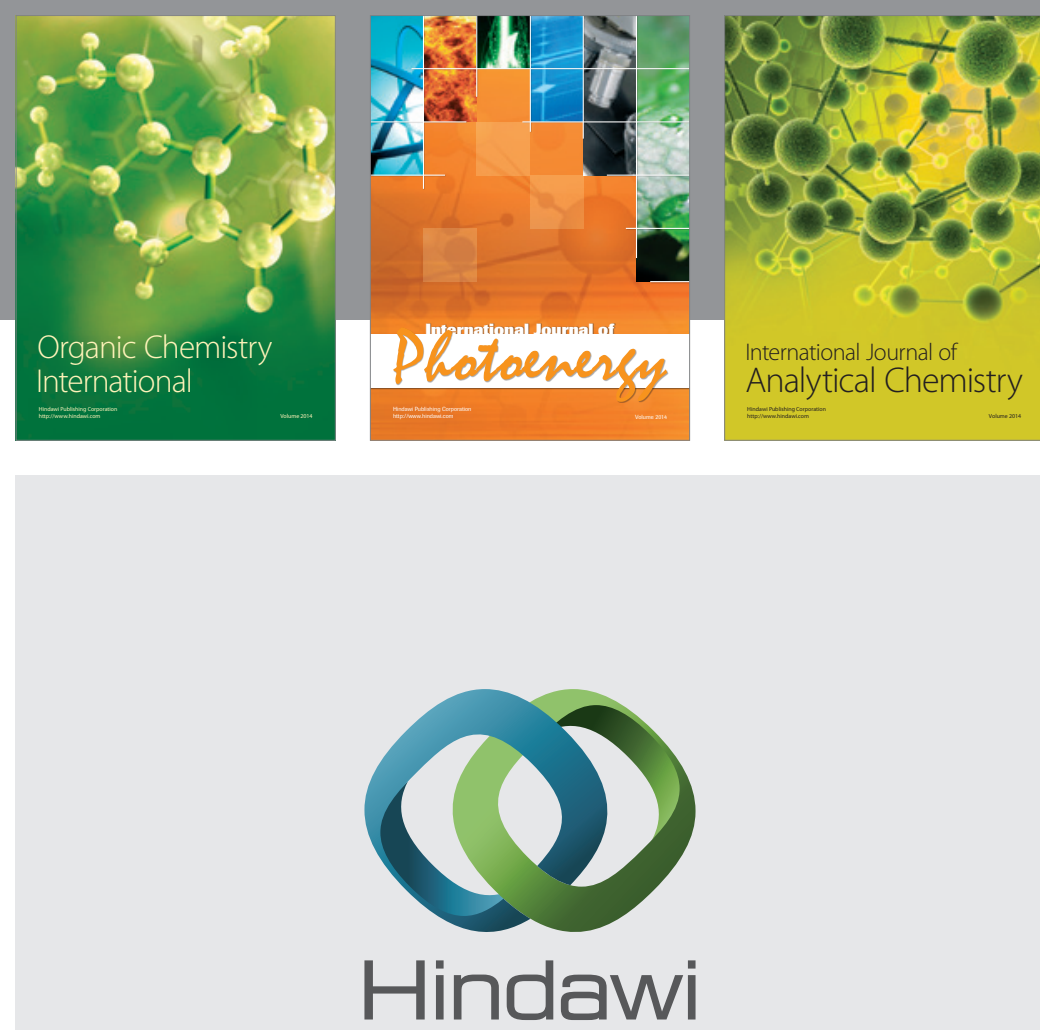

Submit your manuscripts at

http://www.hindawi.com
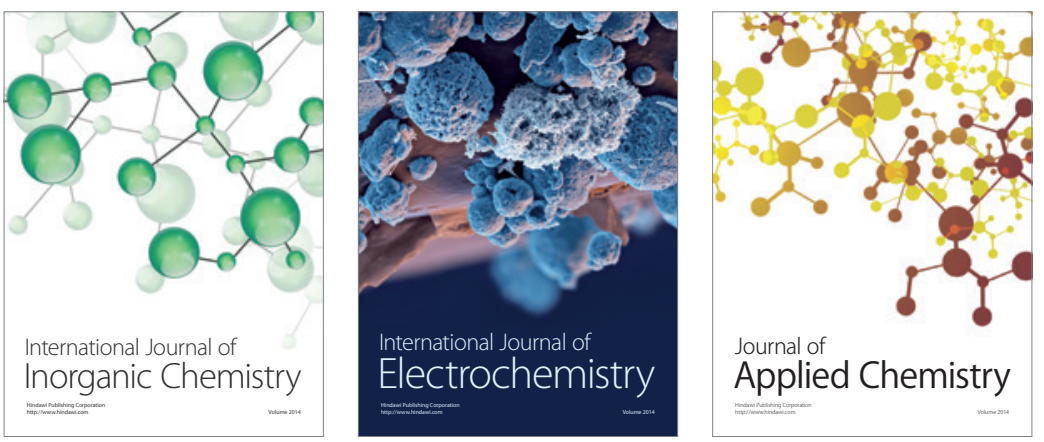

Journal of

Applied Chemistry
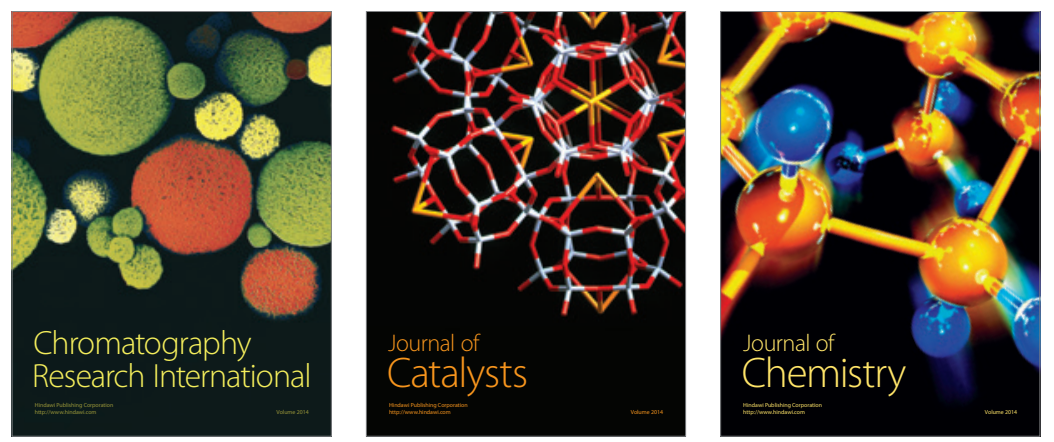
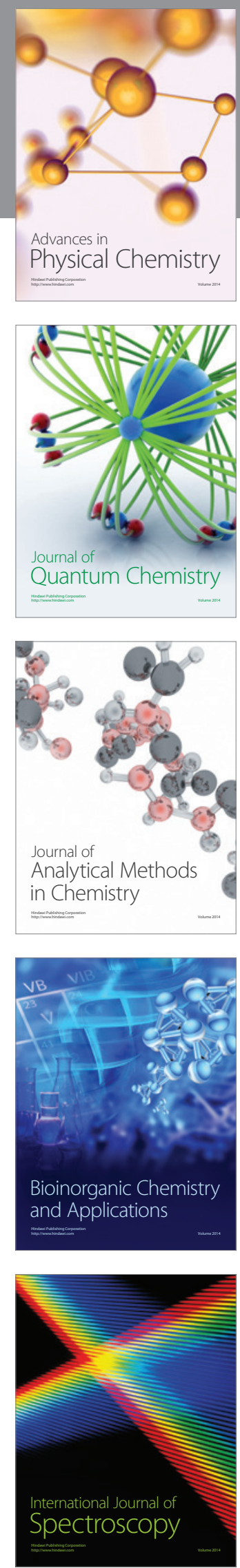